\title{
Movilidad rural urbana rural como fenómeno configurador de dinámicas socioespaciales alternativas. Un estudio de caso en el municipio de Manizales, Caldas, Colombia ${ }^{1}$
}

Rural urban rural mobility as originatorevent of alternative socio spatialdynamics. A case study in the municipality of Manizales, Caldas, Colombia

Marlon Javier Méndez Sastoque ${ }^{2}$

\section{Resumen}

En el marco de las múltiples interacciones entre lo rural y lo urbano, el artículo aborda un asunto en particular: la movilidad rural-urbano-rural concebida como acción configurante de dinámicas socioespaciales alternativas. Como supuesto básico se asume que estas resultan del cruzamiento crítico, comparativo, simbólico y funcional de habilidades, informaciones, conocimientos, roles, contactos, creencias, normas y valores calificados como rurales o urbanos, todos adquiridos, en sus trayectorias de vida, por sujetos que migran del campo a la ciudad, y que posteriormente optan por retornar al campo. En este contexto, en concordancia con los resultados de investigación, el artículo describe y analiza cómo el acervo cultural urbano, en este caso permanentemente confrontado con el acervo cultural rural, permea e influencia la readaptación de los retornados al sitio rural de origen, estimulando la configuración de espacios físicos y simbólicos plurilocales de vida. Como vía metodológica se recurrió a la entrevista en profundidad desde un enfoque biográfico.

1 El artículo hace parte del proyecto: Ruralidades en disputa en la región cafetera del municipio de Manizales, Colombia. Grupo Centro de Estudios Rurales (CERES).

2 Doctor en Desarrollo, Agricultura y Sociedad. Filiación Institucional: Docente del Departamento de Desarrollo Rural y Recursos Naturales de la Facultad de Ciencias Agropecuarias de la Universidad de Caldas. Miembro del Grupo CERES y del Instituto de Investigaciones en Ciencias Sociales (ICSH) de la misma universidad. País: Colombia. Correo electrónico: marlon.mendez@ ucaldas.edu.co 
Palabras clave: Adaptación cultural, articulación rural-urbana, espacios plurilocales, migración campo-ciudad, sociedades rurales.

\begin{abstract}
In the context of the multiple interactions between the rural and the urban, the article addresses a particular subject: the rural-urban-rural mobility as supporter of alternative socio-spatial dynamics. It is assumed that these results from the critical, comparative, symbolic and functional crossing of capabilities, information, knowledge, roles, contacts, beliefs, norms and values classified asrural or urban, all acquired for country-to-city immigrants intheir pathsof life, individuals who choose to return to the field. In thiscontext, consistent with research findings, the paperdescribes andanalyzes how theurbancultural heritage, in this case permanentlyin conflict withruralcultural heritage, permeates and influences the readjustmentof returneesto therural siteof origin, stimulatingthe configuration of the plurilocal physicaland symbolic spacesof life. The in-depth interview, with biographical approach, was the main methodological guide.
\end{abstract}

Keywords: Cultural adaptation, rural-urban articulation, plurilocal spaces, city-to-country migration, rural societies. 


\section{Introducción}

En el marco de las interacciones entre lo rural y lo urbano, y asumiendo como hipótesis que los sujetos de procedencia rural que retornan a su espacio de origen integran a sus estrategias de reproducción socioeconómica parte del conjunto de conocimientos, relaciones, comportamientos, bienes, afectos y actitudes derivadas de su experiencia de vida en la ciudad (conjunto en esta investigación reconocido como acervo cultural urbano), lo cual repercute, transformativamente, sobre el diario acontecer en el sitio de retorno, el objetivo del artículo es presentar, desde una perspectiva comprensiva, las diversas estrategias de readaptación de los actores aquí llamados "retornados" al escenario rural de origen, y los efectos de su puesta en práctica sobre la cotidianidad social local.

El análisis muestra la forma en que dicho acervo cultural permea e interviene transformativamente algunos aspectos de la sociabilidad comunitaria, sobre todo a partir de la puesta en duda de algunas normas y valores operantes en el contexto rural, mas ahora críticamente revaluados a la luz de lo experimentado en la ciudad. Además, considerando la permanencia de los lazos entre quienes se van y aquellos que se quedan, así como la indefinición persistente entre quienes retornan al campo respecto a "ser un poco de aquí y de allá", lo aquí expuesto busca poner de relieve la configuración de espacios plurilocales de vida, como hecho que configura dinámicas socioespaciales alternativas.
Como fundamento teórico se asume que la construcción de dichos espacios plurilocales necesita ser pensada a partir de una concepción reticular (Saquet \& Mondardo, 2008). En este caso, la formación de espacios alternativos de vida se soportarían en procesos que vinculan tanto material como inmaterialmente los espacios físicosociales de origen, destino y posterior retorno, a partir de redes de relaciones sociales entre quienes se van, se quedan y regresan, compuestos por líneas y puntos específicos de encuentro que los dirigen entre un "aquí" y un "allá" (rural, urbano e incluso rurbano) en virtud de sus distintos intereses. Como fue corroborado por la investigación, se trata de un fenómeno que provoca alteraciones en las relaciones interpersonales, en las relaciones de producción y entre los sujetos y su ambiente físico, hecho que a su vez implica la emergencia de nuevas relaciones de poder. Una vez dotados de un acervo cultural urbano, quienes retornan restablecen relaciones con los grupos a los que en la partida físicamente abandonaron, pero que, de una manera u otra, siempre llevaron consigo (Sayad, 2000). Se trata de grupos a los que se vuelve a entrar y en los que es preciso imponerse, aprender a conocer $\mathrm{y}$, cuando sea el caso, dominar.

Como fundamento empírico, lo escrito se sustenta en resultados parciales de una investigación más amplia cuyo objetivo fue identificar las múltiples ruralidades confluyentes en el municipio de Manizales, Caldas, Colombia (Figura 1). En el marco de este estudio se tuvo como objetivo establecer las consecuencias de 
la interacción conflictiva y solidaria entre actores portadores de representaciones disímiles acerca del espacio rural y el modo rural de vida, que con el retorno de sujetos de la ciudad al campo emergió como tema y fenómeno de pesquisa.

Sin desconocer la existencia de múltiples razones que estimulan la migración (respuesta a factores políticos, bélicos, socioeconómicos, ambientales, naturales, culturales, entre otros, que inducen la movilización voluntaria o involuntaria), lo expuesto aplica para sujetos que, deliberadamente, optan por desplazarse del campo a la ciudad, tomando la decisión, un tiempo después, de regresar al sitio rural de origen, resolución tomada sin ninguna presión externa que ponga en peligro la propia sobrevivencia o la de la familia, como amenazas contra su vida o la de sus dependientes. En este escenario limitado, quienes siguen la dirección migratoria rural-urbano-rural, lo hacen porque a su libre criterio resulta conveniente en su momento. Como factor común, la

Figura 1. Ubicación del sitio de estudio. En verde localización de Caldas en Colombia. En gris intenso la zona rural de Manizales y en rojo la zona urbana.

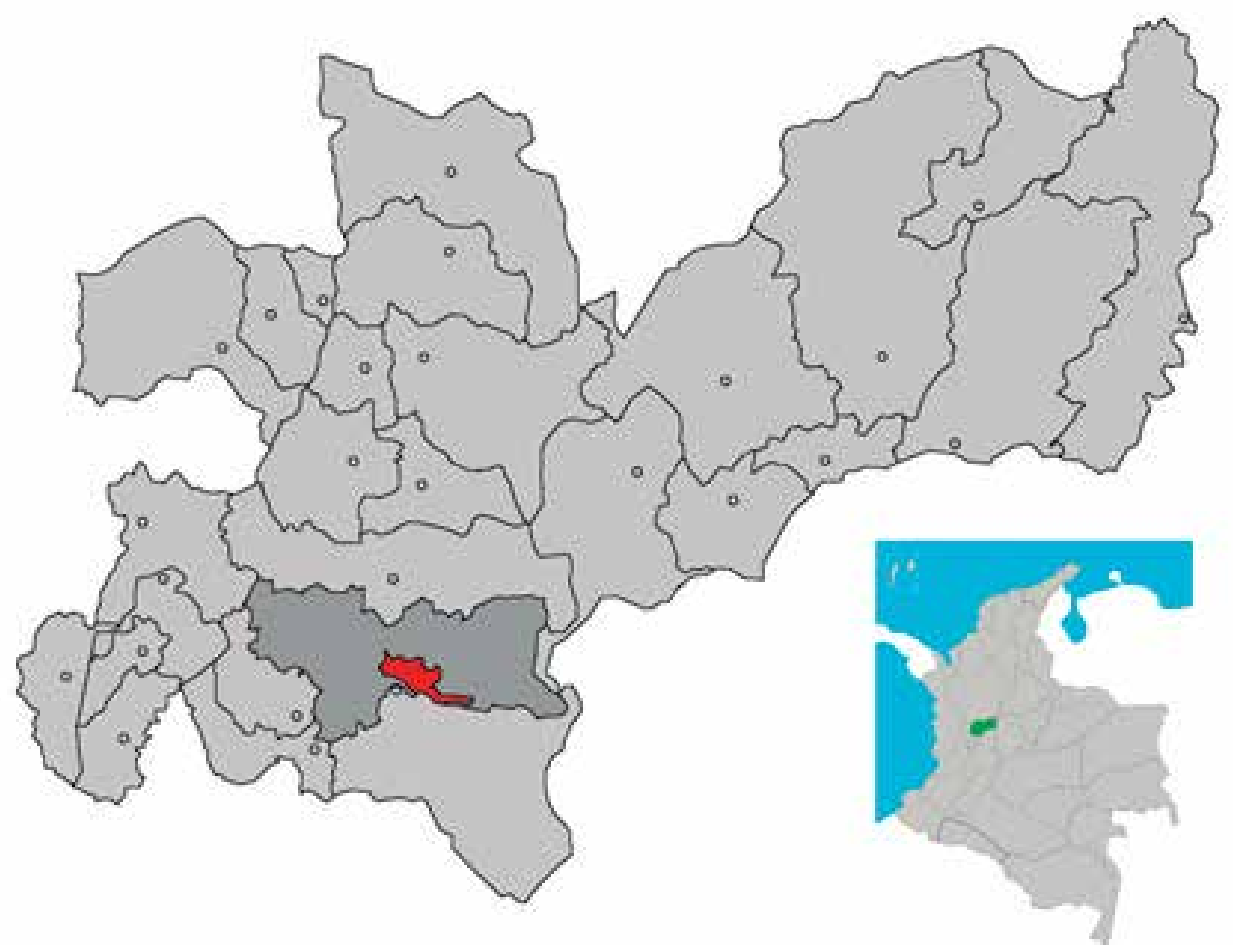

Fuente: http://fr.wikipedia.org/wiki/Fichier:MunsCaldas_Manizales.png\#filelinks 
decisión de salir del campo obedece a factores de índole económica y cultural: mejorar el nivel de vida mediante el acceso a un empleo mejor remunerado, elevar el nivel educativo y de formación propio o familiar, principalmente, decisión usualmente amparada en la existencia de vínculos familiares generadores de desplazamientos asociativos, en los que algún miembro de la familia o la comunidad local sigue a los que partieron primero. En esta misma línea, el retorno al campo obedece, en primera instancia, a la reconstitución y fortalecimiento in situ de vínculos familiares, atendiendo a llamados de responsabilidad, fidelidad y reciprocidad con quienes se quedaron en el campo.

En cuanto a los sitios de retorno, estos corresponden al mismo lugar de salida (sus casas, las fincas familiares en donde aún viven padres, hermanos e hijos, generalmente consideradas patrimonio familiar). El sitio de regreso, en la vía urbano-rural, es el área urbana de Bogotá (capital de Colombia). En función del considerable número de sitios específicos de retorno, se optó por centrar la investigación en cinco veredas localizadas en el corregimiento Corredor Agroturístico, ubicado al suroccidente del municipio. Estas son: Bajo Tablazo, El Aventino, Agua Bonita, La Violeta y Hoyo Frío, localidades rurales en las que la producción de café, en asocio con plátano, constituye el principal renglón económico para una mayoría de pequeños productores propietarios de fincas que oscilan entre media y dos hectáreas de extensión.
En referencia a la vía metodológica, se recurrió al método biográfico, centrando la atención en las experiencias vivenciadas y explicitadas por el grupo estudiado a lo largo de sus desplazamientos entre el campo y la ciudad. Para esto fue preciso analizar los discursos de los retornados, identificando las implicaciones del proceso de adaptación y readaptación social por el cual pasaron sucesivamente, incluyendo lo acontecido en su retorno al sitio rural de origen. La colecta de información fue realizada a partir de entrevistas semiestructuradas, técnica de inducción analítica que permitió definir, precisar y redelinear los hechos relevantes para efectos de la investigación. También se procedió a la observación participante de aspectos relacionados con la expresión de normas y valores en el trato cotidiano con los otros, vínculos comunitarios de solidaridad y conflicto, maneras de garantizar la reproducción económica y social de la familia, modo de relacionarse con la actividad agrícola, entre los principales.

Una vez identificados los informantes clave (retornados, familiares y miembros de las juntas de acción comunal de cada vereda), se procedió a realizar las entrevistas. En total se hicieron 21, entre agosto de 2009 y mayo de 2010, distribuidas de la siguiente manera: once a retornados, seis a familiares de retornados y cuatro a líderes comunitarios. Entre los rasgos sociodemográficos comunes encontrados entre los retornados informantes están: edad entre 32 y 43 años, y estadía de tres a cinco años en la zona 
urbana de Bogotá, antes de su retorno al sitio rural de origen. Se consideró que este tiempo (ahora pretérito) de permanencia en la ciudad fue suficiente para asegurar una adecuada inmersión en la dinámica de vida citadina, expresada en la internalización de ciertos rasgos correspondientes al acervo cultural urbano, asunto primordial en la investigación. En este caso, cimentado en lo expuesto por Abreu (1998), como fundamento teórico se asume que el pasado - en esta ocasión asociado a la vivencia urbana que precede al retorno- constituye un soporte sólido en la búsqueda de las particularidades de las espacialidades alternativas resultantes de la movilidad socioterritorial, y está todavía presente en la cultura, el pensamiento, la conducta y el quehacer cotidiano de quienes optan por volver al campo.

Con las preguntas orientadoras se pretendió reconocer la influencia del acervo cultural urbano incorporado por los retornados en relación con los siguientes campos de interés: los cambios suscitados en el perfil ocupacional, la incorporación de innovaciones tecnológicas y sociales, la forma de relacionarse con sus congéneres del campo, los comportamientos y actitudes frente al sistema de normas operante en el sitio de origen, la valoración y significación del ámbito rural, la conservación, ruptura y creación de nuevas redes de apoyo endogámicas y exogámicas, las percepciones construidas acerca de las dimensiones urbana y rural, entre los principales.

\section{Desarrollo y discusión}

Sin desconocer que en la vida cotidiana no llegan a aislarse unos de otros, como alternativa de lectura del fenómeno en estudio, lo resultados expuestos giran en torno a tres contextos básicos de interacción social, en conjunto asumidos como teatro o escenario de expresión de los aspectos arriba señalados. Estos son: a) el productivo-ocupacional, b) el culturalcomportamental y c) el interpersonalrelacional, escenarios sobre los que se informa a continuación.

\section{Contexto productivo- ocupacional}

Apropiando el proceso migratorio como una oportunidad privilegiada de aprendizaje, como resultado de la vivencia migratoria, los sujetos involucrados, bien sea consciente o inconscientemente, pueden llegar a (re)construir y transformar las visiones, opiniones, conocimientos y habilidades usadas en su quehacer cotidiano. En relación con las habilidades y saberes adquiridos después de una experiencia de vida urbana, los sujetos que retornan al campo traen consigo una serie de conocimientos, habilidades y saberes orientadores de prácticas ocupacionales distintas a las tradicionalmente agrícolas ejercidas antes de la partida. A partir del conocimiento logrado, sin que esto quiera decir que no existieran antes, algunos retornados optan por incorporar a las estrategias familiares de reproducción socioeconómica actividades de orden no-agrícola o para-agrícola, instaurando 
o incentivando la adopción de modelos ocupacionales pluriactivos:

"Cuando regresé a la finca de mis papas, yo seguí con el cultivo de café, que siempre ha sido el sustento de la familia. Pero eso no quiere decir que yo sólo me quedara en eso. Allá [en Bogotá] yo aprendí a manejar carro y llegué a manejar un taxi en las noches, por lo que aprendí del negocio. Por eso, con los ahorros que tenía y un préstamo que me hizo mi mamá, compré un carrito de segunda a plazos, y en eso también trabajo hoy, llevando y trayendo gente de acá a Manizales, o llevándoles el plátano hasta la galería" (Entrevista a retornado de Bogotá a la vereda Hoyo Frío).

Durante su estancia en la ciudad, como parte de las estrategias de adaptación a ese nuevo contexto, los retornados se ven obligados a incursionar en múltiples escenarios ocupacionales no agrícolas, en los que su experticia agrícola y pecuaria no resulta profesionalmente adecuada. Se trata de actividades básicamente de subsistencia, que aunque lucrativamente puedan ser poco significativas, en términos de adquisición de experiencia y conocimiento del medio urbano, resultan de alto valor.

Como factor distintivo, en la mayoría de los casos revisados, el bajo grado de escolaridad los condujo a ejercer labores demandantes de baja o mínima escolaridad, entre los que destacan el servicio doméstico (en casas de familia, oficinas, cafeterías y restaurantes), sobre todo para las mujeres, y celaduría (en casas, edificios y talleres automotores), oficios en obras civiles, en la categoría de auxiliares o "toderos", para el caso de los hombres. A esta lista se agrega la incursión en el comercio informal como vendedores ambulantes de café, golosinas, artículos variados (alimentos procesados y preparados al momento, ropa, accesorios para el cabello, películas y CD de música ilegales) en casetas ubicadas sobre andenes o parques de sectores comerciales en el centro de las ciudades de acogida.

Por su parte, algunos que van un poco más allá, deciden combinar varias de estas mismas actividades, con otras de orden formativo, optando por culminar los estudios primarios o medios vocacionales o por cursar programas de formación técnica y tecnológica en diferentes áreas: panadería, mecánica automotriz, electricidad, informática, enfermería, auxiliar de preescolar, costura y construcción, principalmente.

Analíticamente, en el contexto del retorno del campo a la ciudad, se trata de aprendizajes que incentivan y favorecen la adopción de estrategias pluriactivas de reproducción socioeconómica, fundamentadas en la puesta en operación de esa serie de saberes, habilidades y destrezas, adquiridos o reforzados durante la estancia en el entorno urbano, con consecuencias no solo individuales sino también colectivas. En el lugar de estudio, un hecho ilustrativo tiene que ver con la oferta de servicios recreativos y de ocio, como es el caso de discotecas y salas de juegos electrónicos, actividades catalogables como de origen 
urbano, mas ahora instauradas en un entorno rural en el que pueden asumirse como una novedad:

"Yo sé que joven es joven en el campo o la ciudad. Al joven le gusta la fiesta, salir un domingo o un sábado, descansar del colegio, llevar a la novia a pasear a algún lado. Por eso yo pensé: ipor qué no montar aquí algo para que ellos se vengan, sin tener que ir hasta Manizales [a la zona urbana del municipio]? Con una plata que tenía arreglé la casa y monté un negocio. Primero fue una tiendita para vender cerveza y gaseosa. Luego hice otros arreglos adentro y monté una pista de baile, con juego de luces, como a ellos les gusta" (Entrevista de retornado de Bogotá a la vereda La Violeta)

Se trata de actividades permeadas por el acervo cultural urbano, manifiesto en emprendimientos más de orden terciario que primario, asociados a la prestación de múltiples servicios demandados por los habitantes del campo, que responde a sus necesidades y querencias. Además de las señaladas, actividades y servicios como tiendas y minimercados, venta de cosméticos por catálogo, venta de insumos agrícolas, panaderías, mecánica automotriz, así como servicios de transporte colectivo de personas y productos de cosecha, figuran entre las principales actividades no agrícolas o para-agrícolas localmente realizadas, dispuestas a responder a las demandas de los miembros de las comunidades rurales, que a veces pueden pasar inadvertidas para un observador lego.
Lo anterior permite deducir que, a partir de la experiencia urbana, ciertos retornados consiguen ver a sus congéneres rurales desde otra perspectiva no siempre tan usual: además de productores (agrícolas), perfil con el que comúnmente son tipificados los pobladores del campo, estos también son percibidos como consumidores de una alta gama de bienes y servicios normalmente concentrados en el entorno urbano. Esta situación, en términos de readaptación al entorno rural, puede ser concebida como una ventaja comparativa de los retornados frente a los que no han tenido una experiencia urbana, ganancia resultante de la apertura hacia otras posibilidades, brindada por la expansión tanto física como mental derivada de las vivencias citadinas.

Algo similar ocurre con la aplicación de los saberes aprehendidos mediante el acceso a la formación técnica para el trabajo. Quienes retornan encuentran o avizoran en el campo posibilidades de acción profesional, con intenciones que superan el beneficio propio o individual. Este sería el caso de las jóvenes formadas como auxiliares de enfermería que regresaron y fueron ubicadas al frente del puesto de salud (hecho acontecido en la vereda El Aventino). En este caso, la competencia adquirida se convierte en insumo para la readaptación al espacio social rural, hecho individual con repercusión colectiva, en la medida en que responde a una necesidad comunitaria.

Con ambos casos, el estudio pone en evidencia cómo el acervo urbano acumulado representa un factor de producción. 
Adoptando lo expuesto por Coleman (1990), como otras formas de capital, al retornar de la ciudad al campo, este permite a quienes lo poseen obtener ciertos beneficios, los cuales pueden extenderse al plano comunitario, poniéndose al servicio de causas colectivas.

Con todo, es necesario tener en cuenta que estas aptitudes y actitudes no son generalizables a todos los retornados, pero sí evidentes en algunos que, encontrando eco en el medio en que se desenvuelven, hacen uso de las capacidades adquiridas o perfeccionadas durante su estadía en la ciudad en beneficio propio o colectivo. Aquí es de suma importancia considerar que por más que se posean o se hayan adquirido múltiples habilidades, es el medio social el que da la oportunidad de expresarlas, activarlas y usarlas para diversos fines. En este orden, se trata de un medio en el que se manifiestan no solo circunstancias asociadas al hacer, sino también relacionadas con la formas de ser, pensar, actuar e interactuar con los otros, asunto que se discute a continuación.

\subsection{Contexto cultural- comportamental}

En el proceso de readaptación de los retornados al campo, lo propio y lo ajeno se compara, mide y contrasta, identificando cambios tenues o marcados en relación con lo dejado atrás (Greber, 2006). Se trata de un proceso readaptativo que se da en forma gradual, en donde, en ciertas ocasiones, costumbres de la cultura de origen tienen que ser reaprendidas, asemejándose a lo que ciertos autores reconocen como choque cultura a la inversa (Boekestijn, 1988; Yamada \& Singelis, 1999; Landis, 2008; entre otros). Proceso a partir del cual quienes retornan se vuelven más críticos del entorno físicosocial inmediato del que alguna vez partieron. Sobre este supuesto, en el marco de la movilidad rural-urbana-rural, el acervo cultura urbano podría entrar en conflicto con el acervo rural de origen, mas también, por contrastación, servir de insumo para el redescubrimiento o la revaloración de ciertas manifestaciones culturales reconocidas rurales, hechos evidenciables en algunas actitudes emergentes en el marco de la interacción social.

Un caso recurrente en el sitio de estudio tiene que ver con la postura crítica asumida por varios de los retornados en relación con la manera como operan las agencias gubernamentales y no gubernamentales de extensión, en contraste con la postura pasiva y conformista que, según sus propias lecturas, asumen la mayoría de sus congéneres del campo. El reparo agudo por parte de ciertos retornados a la "forma amañada" de distribuir los recursos, a los limitados alcances de los proyectos de desarrollo agrícola y rural, a las relaciones clientelistas predominantes en la toma de decisiones, entre las principales circunstancias problemáticas reconocidas y rechazadas al interior de las comunidades. Muestra de ello:

"Yo le digo al presidente de la Junta [Junta de Acción Comunal] que hable más de frente con la gente de la UMATA, que les 
reclame porque por aquí vienen poquito, que les digan que a ellos les pagan para que estén aquí ayudándole al campesino, que lo que ellos nos dan no es un regalo sino un derecho que nosotros tenemos. Yo les digo que uno no se puede quedar callado, ver que las cosas van mal y quedarse sin decir nada..." (Entrevista a retornado de Bogotá a la verdad Bajo Tablazo).

Se trata de actitudes desafiantes y críticoanalíticas frente al orden preestablecido, casi siempre positivamente valoradas, por lo menos para el caso de estudio, por los miembros de la comunidad en general. Es este reconocimiento socialmente atribuido (ser visto como líder, como "aquel que no le da miedo hablar ni decir las cosas como son", entre otras expresiones usadas por los entrevistados), el que induce a ciertos retornados a participar activamente en escenarios consultivos y decisorios como las juntas de acción comunal, asociaciones de padres de familia y ciertos proyectos impulsados por agencias gubernamentales de extensión, en los que ellos, junto a líderes tradicionales, suelen asumir cargos directivos y de representación. En términos generales, se trata de un reconocimiento que encuentra sus raíces en la valoración positiva de la trayectoria de vida urbana, experiencia vista como otorgante de ciertas capacidades para tomar distancia del statu quo local, cimentado en "aceptar las cosas como son".

En referencia a la actitud desafiante, para el caso de estudio, esta tiene principal eco en la postura adoptada por las mujeres retornadas frente a las normas que generalmente orientan las relaciones de género.

Como fue observado en varios casos, el acervo cultural urbano es activado al interior de la familia, esta vez en relación con la puesta en duda de ciertas normas y tendencias predominantes. La sumisión femenina al mandato masculino, la división sexual del trabajo en relación con el cuidado de los hijos y los oficios domésticos, así como el papel del hombre como principal o único proveedor del hogar, entre otros elementos, hacen parte de lo ahora visto con recelo. Cuando la mujer es la que migra y el hombre quien permanece en el lugar de origen, al retornar, el hecho de haber sido por cierto tiempo cosustentadora económica de la familia (generalmente a partir del envío de remesas), le confiere mayor autonomía y poder de decisión sobre el uso y la consecución de los recursos al interior del hogar. Al cuestionar el papel de proveedor exclusivo tradicionalmente otorgado al hombre, las mujeres retornadas usualmente hacen uso de las capacidades emprendedoras adquiridas fuera del entorno sociocultural rural para plantear y llevar a cabo iniciativas propias y alternativas de generación de ingresos, enalteciendo su papel como agente productivo y no meramente reproductivo, equilibrando, hasta cierto punto, las relaciones conyugales de poder:

"Aquí en el campo se acostumbra a pensar que la mujer siempre es menos que el hombre, que está para servirle a él y criarle los hijos. Pero las cosas no 
son así, cuando yo llegué a Bogotá sola, a la casa de una amiga que es madre soltera, yo me di maña para salir adelante. Trabajé en casa de familia, fui mesera y cociné en un restaurante, me busque mis medios sin ayuda de ningún hombre, y tuve mis recursos para mí y para mandarle a mis papás. Por eso ahora yo no dejo que me vengan a decir que la mujer es solo para estar en casa y cuidar a los hijos y al marido. Las mujeres tenemos con qué trabajar, por lo que en la casa las cosas tienen que ser compartidas..." (Entrevista de retornada de Bogotá a la vereda Hoyo Frío).

Sustentado en lo anterior, asumiendo el entorno físicosocial urbano como un escenario de socialización secundaria (Berger \& Luckmann, 1979), como resultado de su estancia por varios años en la ciudad, podría plantearse que quienes migraron y retornaron llegan a poner en duda lo aprendido, es decir, aquellos comportamientos y actitudes internalizados e institucionalizados inicialmente en el seno familiar y sociocomunitario rural. En este sentido, la relación con un sistema de normas y valores hasta cierto punto diferente, podría activar la ruptura con un orden institucionalizado, mas ahora reinterpretado y deslegitimado en algunos de sus rasgos, siendo esta una explicación coherente con las situaciones antes esbozadas. Sería esta visión crítica del pasado más o menos reciente lo que impulsaría a los retornados a generar cambios en su entorno original, transformaciones orientadas por su experiencia de vida urbana, ahora usada para contrastar, mediar y juzgar lo que anteriormente para ellos resultaba natural o legítimo. Con todo, sin desconocer la validez de las argumentaciones e interpretaciones hasta aquí presentadas, es también preciso relativizar un poco la influencia innovadora y transformadora de los retornados sobre el espacio social de origen. Nociones como transformación e innovación son relativas en sí mismas. Todo depende del referente de comparación tenido en cuenta, así como de la percepción de cambio de los otros. Adoptando esta premisa sería arriesgado atribuir unilateralmente al retorno la causa de las mudanzas acontecidas en el ámbito rural. Es preciso recordar que los retornados no ejercen un influjo por sí solos y en ausencia de otros sujetos y elementos transformadores. En ausencia de los retornados, el medio de acogida, en este caso el medio social rural, puede experimentar cambios conexos a transformaciones de orden global, variaciones que posteriormente pueden ser aceleradas por quienes retornan al campo, como podría ser el caso del emergente cambio en las relaciones de género.

Desde otro ángulo es pertinente recordar que la experiencia urbana, además de incentivar una actitud crítica y desafiante frente a la cultura del lugar de origen y retorno, al mismo tiempo sirve como insumo para el redescubrimiento o revaloración de ciertas manifestaciones culturales reconocidas rurales. De acuerdo con lo evidenciado, desde una perspectiva psicosocial, los retornados suelen demostrar una actitud positiva ante algunos de los matices culturales dejados atrás al marcharse para la ciudad. Esto se 
manifiesta en la revaloración o el intento por recuperar ciertos vínculos sociales, emocionales y afectivos, ahora vistos a la luz de lo extrañado.

En la medida en que no poder contar con el afecto y el apoyo cercano de los seres queridos, sobre todo en situaciones de necesidad (enfermedad, crisis económica, fallecimiento de alguien cercano), constituye un proceso penoso para quien migra, fortalecer o reconstruir las redes familiares y sociales de apoyo, tramas asumidas como un atributo intrínseco del modo rural de vida, constituiría una forma de revalorar la dinámica social rural que los reacoge. A esto se suma las ansias por volver a estar cerca del paisaje, la tierra, la comida, la casa, las faenas agrícolas, elementos dotados de una alta carga emotiva que emerge cuando se está ausente y suele exaltarse al regreso. De igual forma, sustentado en lo expuesto por los entrevistados acerca de la pérdida de estatus durante su estadía en la ciudad (varios de ellos fueron líderes comunitarios o productores agrícolas valorados como prósperos antes de su partida), hacer uso de las posibilidades de ascenso y reconocimiento social ofrecidas por el entorno comunitario rural constituye otra forma de otorgarle valor:

"Yo no es que diga que allá en Bogotá estaba mal, porque yo tenía todo para vivir tranquilo. Yo tenía mi trabajo, me alcanzaba para pagar un arriendo, para mandarle a la familia, pero yo me sentía muchas veces muy solo, quería estar en mi tierra, en el campo, cerca de la familia, del trabajo de la finca. Yo ahora digo que es mejor vivir acá, más tranquilo, con menos ruido, con más seguridad y confianza. Aquí toda la gente se conoce, un vecino es un vecino, si un día me falta algo que mi vecino tiene, unas naranjas, unas guayabas, hasta un pollo, yo sé que, mientras puedan, a uno no se lo van a negar..." (Entrevista de retornado de Bogotá a la vereda Bajo Tablazo).

Sobre lo anterior es preciso tener en cuenta que estos sentimientos, afectos y emociones en referencia a lo dejado atrás $\mathrm{y}$ ahora recuperable a partir del retorno al campo, en muchas ocasiones pueden estar informados por idealizaciones y sobrevaloraciones acerca de ello. Tal vez con el paso del tiempo, la readaptación progresiva al entorno rural, la readopción de ciertas rutinas, el hecho de empezar a ver de manera menos crítica el sistema de normas y valores predominante, entre otras acciones, conducirá a los retornados a añorar aquellas situaciones, con frecuencia también idealizadas, que forman parte de su historia urbana, más cuando se trata de circunstancias y vivencias que ayudaron a estructurar lo que hoy día ellos son. Con todo, es necesario considerar que para quienes regresan, las cosas no serán exactamente igual a como las dejaron antes de partir. Esto porque el espacio no es apenas físico, sino también un espacio vivido cargado de sentimientos, lo que le confiere la característica de ser también socialmente construido. En este contexto, los entornos urbanos y rurales que físicamente dejaron atrás, al volver no serán los mismos que en su momento conocieron. Al presente, producto de la mixtura entra ambos escenarios de vida, 
desde una perspectiva física, psíquica y cognitiva, ambos espacios harán parte constitutiva de otro espacio por ellos mismos asumido como su actual contexto vital o de desenvolvimiento cotidiano, originario de las experiencias adquiridas a lo largo de sus trayectorias de vida.

En términos analíticos, ese nuevo espacio experiencial resultante del papel central de la relación espacio-tiempo en la construcción social de esos nuevos espacios plurilocales de vida, en donde, en palabras de Santos (1980), la acción histórica deja residuos, en este caso derivados de los acervos rural y urbano, en donde lo viejo es recreado en lo nuevo, en un movimiento concomitante de discontinuidad y continuidad, en donde ni lo uno ni lo otro es suprimido, pero sí permeado, criticado, articulado, reapropiado, legitimado, intervenido o parcialmente transformado.

Esto lleva a proponer que los retornados, en términos generales, son sujetos que viven entre esos mundos combinados por ellos conocidos, vivenciados y reconstruidos. Es justamente esa sensación de estar aquí y allá, manifiesta en sus comportamientos, sentimientos, ocupaciones, reivindicaciones e intercambios de elementos materiales e intangibles, lo que informa y orienta la configuración de espacialidades alternativas. Se trata de vínculos e interacciones de carácter continuo y discontinuo, material e inmaterial, que no se pierden o rompen a pesar del retorno y la partida. Como parte de esa interacción, en el ámbito de las relaciones interpersonales, quienes se van y aquellos que se quedan, actores que comparten parte de su historia, permanecen unidos bien sea por lazos fuertes o débiles, dando continuidad a la movilización multidireccional entre lo rural y lo urbano, bien sea física o inmaterialmente, a partir de relaciones creadas y recreadas en el tiempo, asunto que será expuesto a continuación.

\subsection{Contexto interpersonal- relacional}

En términos del establecimiento de diversos lazos entre los retornados y todas aquellas personas con quienes compartieron e interactuaron durante su experiencia urbana (otros migrantes del campo a la ciudad, familiares, congéneres de origen urbano que facilitaron su adaptación a la ciudad, colegas de trabajo, entre las principales detectadas en la investigación), la constitución de redes de intercambio, tramas sociales que permanecen a pesar de la partida, obedece a los principios generales del sistema de dádiva. Lo observado en campo muestra cómo la triple obligación "dar, recibir y retribuir", estructura los diversos intercambios entre los actores involucrados en el proceso de movilidad rural-urbano-rural. Se trata de redes entre familiares, amigos y conocidos, fundamentadas en relaciones de confianza recíproca y fidelidad, principalmente, que, coincidiendo con lo expuesto por Caillé (2002), van más allá del mero intercambio económico. En este sentido, las bases de los intercambios observados no son apenas de carácter económico, es decir, limitadas a aspectos únicamente 
materiales o a valores utilitaristas sustentadas en el cálculo, sino también de índole simbólica, afectiva y colaborativa.

En atención a la historia compartida entre unos y otros del campo y la ciudad, entre ellos usualmente emerge cierto sentido de ayuda, solidaridad, responsabilidad y confianza mutua, sentimientos desarrollados y fortalecidos a lo largo del tiempo, que superan la ubicación en lugares distintos y lejanos. Se trata de un intercambio que no solo responde a la satisfacción de necesidades, sino que involucra lazos afectivos y emociones, así como esperanzas de ayuda y acogida en casos de un nuevo retorno a la ciudad: "Martha fue mi compañera de trabajo en Bogotá, ambas trabajábamos en un mismo edificio [como empleadas domésticas]. Ella es una de mis mejores amigas, a pesar de estar un poquito lejos. Con ellas nos llamamos seguido y nos contamos cómo va la vida. Cuando sé que alguien va para Bogotá a hacer cualquier cosa, siempre trato de mandarle alguna cosita, y ella también me manda algo. Yo la he invitado muchas veces a venir, pero ella no ha podido por lo lejos. Yo espero que cuando mis hijos crezcan y les dé por irse, tal vez para Bogotá a buscar trabajo o a salir adelante, tengan allá alguien que les pueda dar la mano, que sea alguien de confianza que los pueda ayudar y orientar..." (Entrevista de retornada de Bogotá a la vereda El Aventino).

En términos generales, recurriendo a los argumentos de Mauss (1993) en relación con la obligación social existente en los intercambios concretos entre los sujetos sociales, lo anterior muestra intercambios aparentemente voluntarios, libres y gratuitos, pero en el fondo interesados y obligatorios, regulados a partir de normas implícitamente dictadas, que yendo más allá de lo económico, involucran elementos de índole afectiva y simbólica. En este caso, manifestar que se sigue estando aquí y allá, así no sea de forma presencial; que el vínculo afectivo permanece a pesar de la distancia; que la decisión de ayuda mutua sigue firme; que vivir ahora en el campo o la ciudad no es una excusa para el olvido mutuo, entre otras demostraciones, figuran entre dichos elementos más afectivos que económicos, pero que en sí guardan cierto interés de orden colaborativo o solidario. Desde este ángulo, el interés estaría puesto en los beneficios que los individuos reciben a partir de su permanencia en las redes, mas también en mantener la sociabilidad que da sustento a las redes de confianza e intercambio.

De acuerdo con lo observado, la unidad básica de interacción e intercambio suele ser el hogar, noción no limitada a la unidad física de residencia común, sino entendida como un conjunto de relaciones sociales cambiantes que define una serie de obligaciones mutuas destinadas a contribuir a la reproducción socioeconómica de sus miembros (Mingione, 1994), en este caso indiferentemente situados en el campo y la ciudad, a partir del diseño y puesta en operación de distintas estrategias. Para el caso de estudio, entre estas estrategias destaca una en particular: el ingreso a la escuela y la elevación del grado de escolaridad como mecanismo de movilidad social ascendente, hecho 
que muchas veces implica el traslado de los jóvenes a la ciudad como forma de acceso a instituciones de formación técnica, tecnológica y universitaria, siendo esta última la oportunidad más escasa. En este contexto, la escuela frecuentemente aparece como alternativa familiar de mejoramiento individual y colectivo. Al interior de la familia, la integración al sistema escolar es usualmente acogida como estrategia de superación y distinción, premisa que otorga a la educación de los hijos el papel de punto o factor de quiebre de los ciclos de reproducción social de algunas de las condiciones de desventaja (pobreza, especialización agrícola, inequidad de género, entre otras) generacionalmente heredadas.

Analizando lo hallado, desde la perspectiva intergeneracional, la escolarización es asumida como estrategia de escape. Las generaciones precedentes, de las cuales hacen parte varios padres y madres retornados, confían en que, mediante el estudio, los niños y jóvenes rurales logren forjar proyectos de vida que vayan más allá de lo predeterminado: la vida en un contexto ocupacional agrícola, para muchos asociado a pobreza, atraso y estancamiento social. Sobre esta lógica, asumiendo la articulación de los jóvenes al circuito migratorio campo-ciudad como un futuro casi ineludible, los padres preparan a sus hijos para incursionar en el escenario urbano en mejores condiciones que sus antecesores.

En este caso, como mecanismo de acceso al capital educativo, la red de apoyo es puesta en operación. Generalmente los retornados activan sus contactos familiares y de amistad, en busca de ayuda para que sus hijos o los de otros miembros de la comunidad puedan "acomodarse" en la ciudad, ahora bajo la tutela de gente de su confianza y aprecio. En términos analíticos, estrategias como la descrita mantendrían la expectativa de facilitar o suavizar la adaptación de los nuevos migrantes del campo a la ciudad, acción básicamente orientada por una actitud protectora derivada del conocimiento experiencial de quienes optaron por volver. Podría pensarse que dicha actitud mantiene un carácter dual, en la medida en que, fundamentada en el conocimiento de las dificultades que implica la adaptación de los sujetos de ascendencia rural al medio urbano, en vez de estimular la retención, alienta la salida de esos nuevos migrantes, mas ahora intentando mitigar el traumatismo al que tendrían que enfrentarse.

En otro plano igualmente familiar, la investigación permitió observar que la activación de las redes plurilocales de apoyo también gira alrededor de la responsabilidad de los hijos y otros miembros de la familia, en relación con el cuidado de los padres en su condición de adultos mayores. Cuando la familia nuclear compuesta por padres e hijos es la que migra en su totalidad del campo a la ciudad, además del costo económico, esta debe asumir los costos afectivos derivados de la angustia emocional generada por la separación de los padres que viven la etapa de vejez sin la presencia de sus descendientes directos. En este caso, la vejez de los padres pone de ma- 
nifiesto la norma implícita en la que la reciprocidad es puesta en práctica en el ámbito familiar. Los hijos, únicamente receptores en la infancia y la juventud, como adultos pasan a ser receptores y dadores, hasta que los padres llegan a la vejez, pasando ellos a ser los receptores (Portugal, 2007). En este contexto, el estudio sugiere que cuando los hijos han migrado del campo a la ciudad, el sentido de responsabilidad hacia sus padres constituye un motivo de retorno de algunos de los miembros de las familias migrantes. Mientras unos permanecen en la ciudad en calidad de sustentadores económicos, otros retornan al campo para asumir el cuidado de los padres, afianzando, con esta acción, la red social fundamentada en los lazos de consanguinidad, gratitud y adeudo:

"Yo me regresé para cuidar a mi mamá, porque ella ya está muy viejita y necesita que alguien se dé cuenta de ella. Mi esposo y yo nos pusimos de acuerdo en eso. Él se quedó allá [en Bogotá] con mi hija mayor, que está estudiando en el SENA, y yo me vine con la menor, que todavía está de seis años. Él es el que nos manda para el sustento, una parte para la familia mía y otra para la de él..." (Entrevista a retornada de Bogotá a la vereda La Violeta)

En circunstancias como la anterior, que también se manifiesta en situaciones ligadas al impacto emocional que genera separarse del cónyuge o de los hijos que permanecen en el lugar de origen, la división sexual del trabajo al interior del grupo doméstico suele determinar qué miembros de la familia permanecen en la ciudad y cuáles regresan al campo para ocuparse del cuidado de los adultos mayores. En estos casos, de acuerdo con lo observado en campo, son principalmente las mujeres quienes retornan, situación que reproduce su rol tradicional de cuidadoras del hogar y la familia (rol doméstico), así como de salvaguardas de las relaciones afectivas a distancia, mientras los hombres permanecen en la ciudad cumpliendo su papel de proveedores de los recursos necesarios para satisfacer las necesidades familiares. Específicamente, son las madres e hijas quienes con frecuencia retornan para ponerse al cuidado de los abuelos paternos y maternos, sumando fuerzas para la consolidación de otros arreglos familiares, como los relacionados con el cuidado de los hijos de otras mujeres que han optado por dejar el campo.

Situaciones como las señaladas muestran cómo en el marco de la movilidad ruralurbana-rural, las familias permanecen como institución adaptándose a las circunstancias y buscando nuevas formas de fortalecer los vínculos familiares tanto económicos como afectivos y de gestión del cuidado. En términos generales, dichos arreglos familiares, en buena parte motivados por la movilidad socioespacial, ilustran como no es cabalmente necesario residir en el mismo sitio para conjuntamente definir estrategias de reproducción física y social de la familia. Lo anterior da pie para plantear que residir en un mismo lugar tampoco es estrictamente necesario cuando se trata de redefinir esos espacios ampliados y cotidianos de 
vida, espacios que trascienden los límites de lugar, en este caso catalogados como rurales y urbanos.

Otra expresión de esta misma movilidad, ahora más específicamente desenvuelta en la dirección ciudad-campo, tiene que ver con el traslado temporal de sujetos de origen urbano al entorno rural con motivaciones principalmente económicas. A manera de ilustración, asunto observado con frecuencia en campo, en épocas de cosecha de café, cuando la demanda de mano de obra es alta, activando y haciendo uso de la red de relaciones preexistente, algunos retornados proponen y convocan a amigos y familiares residentes en la ciudad a incursionar en las faenas agrícolas, casi siempre en calidad de recolectores. En este contexto, comunicar a los congéneres citadinos la existencia de oportunidades de trabajo en las localidades rurales, así como facilitarles la estadía y entrenarlos para el desempeño de las labores agrícolas requeridas, aparecen entre las principales formas de movilidad interactiva, hecho que habla del resquebrajamiento funcional de las fronteras entre lo urbano y lo rural. En este caso, el ingreso de sujetos con trayectorias ocupacionales urbanas o no-agrícolas al espacio agroproductivo rural indicaría la constitución de espacios cotidianos o temporales de vida que combinan uno y otro escenario.

Similarmente, desde el ángulo que apunta de lo rural a lo urbano, el mismo sentido se evidencia cuando migrantes del campo a la ciudad, haciendo uso de su acervo cultural rural, instruyen e inmiscuyen a actores citadinos en prácticas agrícolas ejecutadas en su mismo entorno, promoviendo, de esta forma, la agricultura urbana como alternativa aportante a la seguridad alimentaria de quienes habitan en las urbes, situación ampliada por Méndez et al. (2005), en otra investigación desarrollada en el mismo sitio de estudio.

Para finalizar, es pertinente no perder de vista que las redes sociales que soportan la movilidad rural-urbana-rural son producto de la interacción humana, condición que vuelve vulnerable la continuidad y manutención de la triada "dar, recibir, retribuir". Siguiendo esta idea y adaptando lo expuesto por Bourdeau (2000), es importante resaltar que dichas redes no corresponden a un arreglo natural, por lo que deben construirse socialmente a partir de estrategias de inversión encaminadas a institucionalizar las relaciones que aseguran el acceso a los beneficios circulantes, costo que no todos estarían en capacidad de cubrir o sostener. Como fue expuesto en este apartado, participar de las redes demanda tiempo y dedicación para estar disponible para los otros, así como una serie de costos materiales que no pueden ignorarse, situación definitiva en los procesos de continuidad, ruptura, adaptación o reelaboración de las relaciones forjadas a partir de los ires y venires entre lo rural y urbano.

\section{Conclusiones}

Comprender la movilidad rural-urbanarural en una localidad específica implica la necesidad de caracterizar una situación 
dinámica y compuesta, fundamentada en la conjunción de dos sistemas de valores, el rural y el urbano, sistemas que se permean y transforman mutuamente, generando múltiples espacialidades mixtas. En esta vía, poner atención al doble enlace rural-urbano/urbano-rural proporciona una adición particular. En primer lugar, introducir el "retorno al campo" como variable analítica, reconocer la circulación de objetos, personas, símbolos, servicios, apoyos y afectos, enfatizando la vía que va de la ciudad al campo, contribuye, hasta cierto punto, a equilibrar la fuerza dada por los estudios de movilidad entre lo rural y lo urbano al desplazamiento unidireccional que va del campo a la ciudad. En este orden, resulta prudente plantear que una narrativa migratoria envolvente debería prestar más atención a la multidireccionalidad de las movilizaciones, considerando que los puntos de partida y llegada consiguen, por lo menos en algunas ocasiones, tomar uno el lugar del otro, activando los efectos del "choque cultural a la inversa" sobre la constitución de otras espacialidades.

Como fue argumentado en este artículo para el caso de los retornados, nuevas actitudes resultantes de la mixtura de vivencias y acervos culturales, además de ampliar su concepción de espacio o mundo inmediato de vida (aquella sensación de ser de aquí y allá, mas también de estar en ambos lados), orientan y condicionan tanto su readaptación al lugar rural de origen como su accionar al interior de la dinámica social local. En este contexto, reintegrarse a un contexto sociocultural que antes les resultaba demasiado familiar, pero que, en virtud de los cambios valorativos, actitudinales y comportamentales, al regreso les puede resultar extraño o apenas parcialmente aceptable, constituye un detonante para la configuración de escenarios socioespaciales alternativos, ahora asumibles como objetos de estudio e indagación sociológica.

Este resultado permite concluir que las nuevas formas de socialización, así como los también nuevos conocimientos adquiridos a partir de la movilidad ruralurbana-rural, contribuyen a configurar, entre los retornados, otras formas de ser, actuar y razonar, sustentadas en las visiones de mundo y concepciones adquiridas a lo largo de sus trayectorias sociales. La suma y conjunción de estos saberes a lo largo de sus historias de vida, en este caso oscilantes entre lo rural y lo urbano, una vez incorporados al diario vivir, pasan a orientar sus conductas, por lo menos parcialmente. Como se evidenció, estas incorporaciones interfieren en la manera de asegurar la reproducción económica y social de la familia y en la forma de constituir relaciones sociales, que incluyen las relaciones al interior del núcleo familiar, la consolidación de lazos de solidaridad y conflicto, la participación en asuntos de interés colectivo, entre los principales factores.

En segundo lugar, apoyado en lo expuesto por Laclau (1993) acerca de la pluralidad identitaria, sería pertinente plantear que las transformaciones generadas por conjunción entre los órdenes rural y urbano precedentes, indicarían la presencia 
de una dinámica social rural abierta capaz de integrar, en ciertas circunstancias, nuevos elementos e identidades sociales. Como fue demostrado, en el marco de las relaciones entre lo rural y lo urbano, las identidades que muestran la pertenencia a uno u otro contexto sociocultural, no pueden ser vistas como algo estático, sino, al contrario, como un constructo móvil, múltiple, personal, autorreflexivo, sujeto a cambios e históricamente definido. En este sentido, y para finalizar, po- dría afirmarse que esa misma dinámica social abierta y permeable a estímulos provenientes de los espacios urbanos, a la vez que da pie a la desarticulación de identidades estables anteriores, posibilita la producción de nuevas identidades. Apreciación coherente con la intención de hacer visibles las rupturas y continuidades de los órdenes socioespaciales de origen (en un primer momento rural y en un segundo, urbano) como fundamento de la constitución de dinámicas socioespaciales alternativas. 


\section{Literatura citada}

Abreu, M. (1998). Sobre a memória das cidades. Território, 3(4), 5-26.

Berger, P. \& Luckmann, T. (1979). La construcción social de la realidad. Buenos Aires: Amorrortu.

Boekestijn, C. (1988). Intercultural migration and the development of personal identity. The dilemma between identity maintenance and cultural adoption. International Journal of Intercultural Relations, 12(2), 83-105.

Bourdieu, P. (2000). Poder, derecho y clases sociales. Bilbao, España: Desclée de Brouwer.

Caillé, A. (2002). Dádiva e associação. En P. Martins. (org.). A dádiva entre os modernos: discussão sobre os fundamentos e as regras do social. Petrópolis, Brasil: Vozes.

Coleman, J. (1990). Foundations of Social Theory. Cambridge: Harvard University Press.

Greber, E. (2006). Procesos migratorios, identidad étnica y estrategias adaptativas en las culturas indígenas en chile: una perspectiva premininar. Santiago de Chile: Cengage.

Laclau, E. (1993). Nuevas reflexiones sobre la revolución de nuestros tiempos. Buenos Aires: Nueva Visión.

Landis, D. (2008). Globalization, migration into urban center, and cross-cultural training. International Journal of Intercultural Relations, 32(4), 337-348.

Mauss, M. (1993). Sociología y antropología. Madrid: Tecnos.

Méndez, M., Ramírez, L. \& Alzate, A. (2005). La práctica de la agricultura urbana como expresión de emergencia de nuevas ruralidades. Cuadernos de Desarrollo Rural, $55,51-70$.

Mingione, E. (1994). Las sociedades fragmentadas. Madrid: MTAS.

Portugal, S. (2007). O que faz mover as redes sociais? Uma analise das normas e os laços. Revista Crítica de Ciências Sociais, 79, 35-56.

Santos, M. (1997). A natureza do espaço. São Paulo: Hucitec.

Saquet, M. \& Mondarto, M. (2008). A construção de territórios na migração por médio de redes de relações sociais. Revista Nera, 11(13), 118-127.

Sayad. A. (2000). O retorno: elemento constitutivo da condição do migrante. Trevessia, 13, 7-32.

Yamada, A. \& Singelis, T. (1999). Biculturalism and self-construal. International Journal of Intercultural Relations, 23(5), 697-709.

Recepción: 4 de noviembre de 2011

Evaluación: 10 de diciembre de 2011

Aprobación. 1 de marzo de 2012 